\title{
The Labor Market Value to Legal Status
}

\author{
Todd A. Sorensen \\ UC Riverside \\ Fernando Lozano \\ Pomona College \\ This Draft: May 2008 \\ Preliminary Draft, Please Do Note Cite
}

\begin{abstract}
We present new estimates of the effect that obtaining legal immigration status has upon the wages of undocumented workers. In estimating the effect of legalization upon wages, we face a number of econometric challenges. First, through the use of rich panel data, we are able to control for the fact that individuals with higher time invariant unobserved ability, which will raise earnings regardless of legal status, may be more likely to obtain legal status. Second, we use a more appropriate counterfactual as a control group against which to compare the outcomes of those who obtained legal status: those who were undocumented in both the first and last periods. Finally, we use two sources of exogenous variation to instrument for the potentially endogenous changes in legal status. Our two sources of variation allow us to identify two distinct labor market effects of legalization: 1) We use a consistent panel of data for both workers who obtained legal status and for those who did not; 2)we are the first to use an instrumental variables strategy that allows us to identify individual specific effects of legal status from the general equilibrium effects on labor markets that follow from a mass legalization.
\end{abstract}

Todd Sorensen is an Assistant Professor at the University of California, Riverside, Fernando Lozano is an Assistant Professor at Pomona College. Please direct correspondence to Todd Sorensen at todd.sorensen@ucr.edu. 


\section{Introduction}

Over the last two years, immigration reform has become one of the most contentious issues facing policy makers. Proponents of sweeping immigration reform typically support "comprehensive immigration reform". This approach involves enacting a package of reforms that would lead to changes in three areas: (1) border control policies, (2) the creation of new and expansions of preexisting guest-worker programs, and (3) a pathway towards legal status for the estimated 11 to 12 million ${ }^{1}$ undocumented migrants currently residing in the United States.

The later of these three proposals is arguably the most controversial. Opponents of reform frequently label such measures as "amnesty". In turn, proponents have responded by tying any change in legal status to an number of conditions. In addition to passing a background check and learning English, migrants would also be required to pay a fine. To the undocumented migrant, this fine would in essence be part of the "price" they are paying to ultimately obtain a green card.

Here, we use various methods and data-sets to estimate the labor market premium to obtaining legal status, i.e. a lower bound of the undocumented workers "willingness to pay" for legal status. Estimating this parameter would be of value to policy makers: setting a fine too low might not garner enough political support to enact a policy, while setting the fine too high might lead to unintended consequences. The primary unintended consequence would be to create a new class of migrant-those who have the opportunity obtain legal status but for whom the financial costs outweigh the benefits. Clearly this would indicate the failure of a policy designed to bring all workers into the legal fold.

In addition to the direct application to policy, measuring the return to le-

\footnotetext{
${ }^{1}$ Pew Hispanic Center Report.
} 
gal status should be of general interest to labor economists for a number of reasons. While early seminal papers in the economics of migration focused on labor market outcomes of migrants ((Chiswick 1978) (Borjas 1985), the most widely cited papers in this area over the last two decades have shifted the focus of study to the effect of migrants on the labor market outcomes of natives. Clearly there are a number of understudied questions regarding immigrants in the labor market that an estimate of the benefit of legal status can help to answer. If immigrants wages increase with legal status, what is this suggestive of? Coincidental changes in occupation may indicate that legal status opens doors to a broader set of opportunities, increasing the quality of employer employee matches. Changes in wages without changes in occupation might indicate that, without proper legal status, employers are in a position of market power over their employees. A finding of no significant change in wages with a change in legal status would indicate that informal labor markets in the U.S. operate efficiently.

There are several challenges involved with estimating the causal effect of legal status on earnings. For starters, most data sets do not allow the researcher to observe legal status. Some prior work uses the Legalized Population Survey (LPS). While this data set provides very good data on those who became legalized, it does not contain observations of those whose legal status did not change.

Consider the familiar missing counterfactual problem: because we cannot simultaneously observe the same individual both with and without legal status, we must come up with a valid alternative counterfactual. Simply comparing with legal status to those without legal status would likely be invalid, as legal status is likely correlated with unobservables affecting labor market outcomes. Others in the literature have used random shocks in immigration law as an 
instrument for legal status.

As in many of these prior studies, we use the Immigration Reform and Control Act (IRCA) as an instrument. IRCA granted legal status to migrants who could prove that they had entered the United States before 1982. Also as in previous work, we use a difference in difference estimate- comparing changes in labor market outcomes for those who receive legal status to changes in labor market outcomes of a comparison group over the same period of time. However, we depart from the literature in the choice of our comparison group: in lieu of using a demographically similar group of individuals (for which the legal status of individuals is unknown). Exploiting the rich data of the Mexican Migration Project (MMP) we are the first to use the changes in labor market outcomes for individuals who remained undocumented while others were becoming legalized.

When estimating the effect of legalization on labor market outcomes, we must be careful to understand exactly what our variation is identifying. In the case of IRCA, it would be difficult to believe that there were not important general equilibrium effects that followed from changing the legal status of millions of previously undocumented immigrants. Here ,by using random variation in legal status that comes both from IRCA and variation in status from other sources, we are able to separately identify the effect of legal status changes on an individuals earnings from the general equilibrium effects that resulted from IRCA.

Our preliminary results indicate that there exists a positive and significant causal effect of legal status on labor market earnings; on the order of about 20 $\log$ points. Our estimate of the magnitude of this effect exceeds prior estimates from the literature. Additionally, we find that while workers as a whole benefit from changes in legal status, agricultural workers do not. This may shed some light on the competitive structure of different labor markets. 
The rest of the paper proceeds as follows: Section 2 discusses prior research on the premium to legal status. Section 3 presents in detail our identification strategy, Section 4 describes our data, Section 5 presents our results, and Section 6 concludes.

\section{Literature}

Since its implementation in 1986, economists have long been interested in the role that IRCA had in the earnings of immigrants both legal and illegal immigrants. For example Rivera-Batiz (1999) compares the cross-sectional differences in earnings between illegal Mexican immigrants from Legalized Population Survey (LPS) with Mexican immigrants from the 1990 U.S. Census. His results find that male illegal immigrants earn wages 14 percentage points less than their legal counterparts, while female illegal immigrants earn wages 26 percentage log points lower than their legal counterparts. Rivera-Batiz further analyzes the longitudinal changes in the earnings of immigrants due to IRCA, and estimates a treatment on the treated estimate that compares an immigrant's earnings before and after the legalization. His results show that for the treated group, the difference in earnings before and after IRCA are 13 percentage points for men, and 17 for women. Importantly, Rivera-Batiz shows that a very small portion of the wage gains from legalization accrue to changes in the demographic characteristics of legalized immigrants.

It has also been argued that IRCA has some unintended consequences in the earnings of illegal immigrants, since IRCA included some provisions that increased the fines to employers who hired illegal immigrants. ? used the Mexican Migration Project to investigate this point. In particular they test whether IRCA hurt the labor market outcomes of illegal immigrants because employers transferred the costs associated with hiring them. Their results suggest that 
after IRCA nonagricultural undocumented immigrants earned $22 \%$ less than their documented counterparts, while agricultural undocumented immigrants earn even $33 \%$ less than their urban counterparts.

Similarly, Kossoudji and Cobb-Clark (2002) analyze changes in the wage determinants before and after IRCA. In their analysis they use the LPS to compare the labor market outcomes of immigrants before and after IRCA, and compare these outcomes with U.S. born Hispanics in the National Longitudinal Survey of Youth (NLSY). Their results suggest that native NLSY respondents experienced a wage growth rate of $34.6 \%$, while the growth rate for the immigrant LPS respondents was $16.9 \%$. These differences in wage growth are likely due to job mobility. In contrast, the wage growth after the IRCA was greater for the LPS sample (11.1\%) than for the NLSY sample (7.1\%). They show that the faster wage growth after legalization for immigrants in the LPS is due mainly to changes in the returns to human capital - in contrast to the results presented by Rivera-Batiz where demographic characteristics played no role in the decrease of legal-illegal gap after IRCA.

Amuedo-Dorantes, Bansak and Raphael (2007) use the same treatment and control groups as Kossodji and Cobb-Clark (2002) to answer the question whether IRCA increased job mobility and reservation wages among the legalized population. They exploit a quasi-experimental framework to show that employment rates fell for men by 5.3 percentage points, while they did not fell for women. Conversely, labor force participation did not changed for legalized immigrant men, but it decreased for legalized immigrant women by 6.5 percentage points. Furthermore their findings show that the returns to English language increased after IRCA, and as in the case of Kassoudji and Cobb-Clark's piece legalization increased the returns to human capital for women but not for men. Economists have also studied other legalization and naturalization pro- 
grams different to IRCA. For example, (Kaushal 2006) investigates the effect that the 1997 Nicaraguan Adjustment and Central America Relief Plan (NACARA) had on the earnings of undocumented immigrants born in Cuba, Guatemala and El Salvador. Using data from the Current Population Survey Merged Outgoing Rotation Groups (CPS ORG), he finds that earnings for immigrants from these countries increased by $4 \%$ after the implementation of NACARA. Importantly, his control group is immigrants in the CPS ORG born in Mexico, other Central America Countries, the Caribbean and Peru, Colombia and Ecuador. Arguably, these estimates will be biased downward from the real effect of NACARA, because in the CPS ORG legal status is not observable and a portion of the treatment group will be polluted by immigrants who were legal before NACARA.

While most of the Economists' interest has focused in analyzing the outcomes of immigrants who move from illegal status to legal status, two more pieces of work are worth mentioning: Gass-Kandilov (2007) uses the New Immigrant Survey to evaluate the changes in earnings of immigrants who first came to the U.S. sponsored by their employers and eventually received a green card. Using natives from the CPS ORG to estimate a propensity score difference in difference estimator she finds that among this group of immigrants a green card increases an wages by 18\%. Similarly, Bratsberg, Jr. and Nasir (2002) al. (2002) investigate what is the value from becoming a naturalized U.S. citizen. Using data from the NLSY, they found that naturalization predicts earnings that are 5.6 percentage points greater than other immigrants. This is mainly because naturalization is positively associated with faster wage growth, white-collar employment and unionized work. 


\section{Identification}

To main purpose of this paper is to identify the causal effect of legal status on the wages earned by a migrant in the labor market. Below, we discuss the estimators we use to obtain consistent estimates of this parameter.

\subsection{Cross Sectional Approach}

The most straightforward approach to estimating the effect of legal status on earnings would be to simply regress earnings on the observed legal status of the migrant, estimating the equation below,

$$
y_{i}=L_{i} \gamma+X_{i} \beta+e_{i}
$$

where $y_{i}$ represents the $\log$ wage earned by individual $i$. The variable $L_{i}$ is an indicator variable equal to 1 if the migrant is documented, and equal to 0 if the migrant is undocumented. The coefficient $\gamma$ is the labor market return to legal status, and is our parameter of interest. Other characteristics of the migrant are represented by vector $X_{i}$, and the returns to these characteristics are given by vector $\beta$. Unobservables of the migrant that will affect labor market earnings are equal to $e_{i}$.

If $\gamma$ is estimated by OLS, the variation in the data that identifies data is essentially a comparison of the wages of documented immigrants to the earnings of undocumented. The identifying assumption for the OLS estimator is $E[e \mid x, L]=0$; that is, that there is no correlation between an individuals unobservables affecting labor market earnings and the likelihood that the individual has a green card.

The identifying assumption $E[e \mid x, L]=0$ holds only under the heroic assumption that individuals who obtain legal status are randomly selected from 
population (or at least selected on characteristics that do not also determine labor market earnings). If more skilled, intelligent, better motivated, or better informed migrants are more likely to hold green cards, this assumption will be violated.

\subsection{Fixed Effects Regression}

Fortunately, the Mexican Migration Project data that we use (described in the next section) include data on more than one migration spell for most of the individuals in the data set. We can then express our econometric model as a set of two sets of observations

$$
\begin{aligned}
& y_{i 1}=X_{i 1} \beta+L_{i 1} \gamma+e_{i 1} \\
& y_{i 2}=X_{i 2} \beta+L_{i 2} \gamma+e_{i 2}
\end{aligned}
$$

where the time subscripts 1 and 2 represent the values of the variables on the individuals first and last migration, respectively. The term "last migration", used throughout the paper, refers to the individuals most recent migration, and not necessarily their final migration.

We further exploit the panel variation in our data if we express the individuals unobservable characteristics, $e_{1 i}$ and $e_{2 i}$ in terms of two different categories of unobservable characteristics, those that vary across time and those that do not:

$$
\begin{aligned}
& e_{i 1}=u_{i}+\varepsilon_{i 1} \\
& e_{i 2}=u_{i}+\varepsilon_{i 2}
\end{aligned}
$$


where the term $u_{i}$ represents time invariant characteristics, and the terms $\varepsilon_{i 1}$ and $\varepsilon_{i 2}$ represent unobserved characteristics of the individual in their first and last migrations, respectively. Thus, we can express our labor market earnings equations as

$$
\begin{aligned}
& y_{i 1}=X_{i 1} \beta+L_{i 1} \gamma+u_{i}+\varepsilon_{i 1} \\
& y_{i 2}=X_{i 2} \beta+L_{i 2} \gamma+u_{i}+\varepsilon_{i 2}
\end{aligned}
$$

After first differencing the two equations for labor market earnings above, we have the following equations, which when estimated by OLS will produce estimates of $\gamma$ whose consistency is robust to the correlations between (time invariant) individual characteristics and legal status described above.

$$
\Delta y_{i}=\Delta x_{i} \beta+\Delta L_{i} \gamma+\Delta \varepsilon_{i}
$$

Put another way, $\hat{\gamma}$ may produce consistent estimates of $\gamma$ even when $E\left[e_{i} \mid x_{i}, L\right]=$ 0 . Thus, the first differenced fixed effects estimator relies on the much weaker identifying assumption that $E\left[\varepsilon_{i} \mid x_{i}, L\right]=0$; there must be no correlation between time period specific shocks to labor market earnings and the legal status of the migrant.

The variation in that data that will identify $\beta$ now comes from a comparison of those who, between the two migrations we observe in the data, switch from being undocumented status to legal status; i.e. a comparison of changes in the wages of migrants for whom the value of $\Delta L_{i}$ is 1 and those for whom the value of $\Delta L_{i}$ is 0 . 


\subsection{Appropriateness of Control Group}

It is worth noting that $\Delta L_{i}$ will be equal to 0 in two cases: when the migrant was documented in both periods, or when the migrants was undocumented in both periods. It is worth noting that in the data set that we employ, there are for more observations for which $\Delta L_{i}$ is equal to 0 because the migrant was undocumented in both periods than there are for cases when the migrants was documented in both periods. Prior to our paper, the literature has used "always documented non-switches" as the control group to the "switched to legal status" treatment group.

The choice of the "always documented non-switches" in prior work has been driven primarily by the availability of data. A major benefit to using Mexican Migration Project (MMP) data is that the data contains information on earnings on labor market earnings and legal status for both the documented and the undocumented; while data sets such as the Legalized Population Survey (LPS) observe only those who have gone from undocumented status to documented status.

Consider the expected value of the dependent variable in 3 cases:

$$
\begin{gathered}
E_{S}=E\left[\Delta y_{i} \mid L_{1 i}=0, L_{2 i}=1\right]=\Delta x_{i} \beta+\gamma+E\left[\Delta \varepsilon_{i} \mid L_{1 i}=0, L_{2 i}=1\right](9) \\
E_{N_{1}}=E\left[\Delta y_{i} \mid L_{i 1}=1, L_{i 2}=1\right]=\Delta x_{i} \beta+E\left[\Delta \varepsilon_{i} \mid L_{1 i}=1, L_{2 i}=1\right] \\
E_{N_{0}}=E\left[\Delta y_{i} \mid L_{i 1}=0, L_{i 2}=0\right]=\Delta x_{i} \beta+E\left[\Delta \varepsilon_{i} \mid L_{1 i}=0, L_{2 i}=0\right]
\end{gathered}
$$

Two estimators of $\gamma$ are then: 


$$
\begin{aligned}
\hat{\gamma}_{1}= & E_{S}-E_{N_{1}}=\gamma+\left(E\left[\Delta \varepsilon_{i} \mid L_{1 i}=0, L_{2 i}=1\right]-E\left[\Delta \varepsilon_{i} \mid L_{1 i}=1, L_{2 i}=(\mathbb{1}]\right. \text { \&) }\right. \\
= & \gamma+\overline{\Delta \varepsilon_{S}}-\overline{\Delta \varepsilon_{1}} \\
\hat{\gamma}_{0}= & E_{S}-E_{N_{0}}=\gamma+\left(E\left[\Delta \varepsilon_{i} \mid L_{1 i}=0, L_{2 i}=1\right]-E\left[\Delta \varepsilon_{i} \mid L_{1 i}=0, L_{2 i}=(0[\})\right.\right. \\
& \gamma+\overline{\Delta \varepsilon_{S}}-\overline{\Delta \varepsilon_{0}}
\end{aligned}
$$

As long as $E\left[\Delta \varepsilon_{i}\right]=0$ for each of the groups, both of these estimators will be unbiased:

$$
\begin{aligned}
& E\left[\hat{\gamma}_{1}\right]=E\left[\gamma+\overline{\Delta \varepsilon_{S}}-\overline{\Delta \varepsilon_{1}}\right]=\gamma \\
& E\left[\hat{\gamma}_{0}\right]=E\left[\gamma+\overline{\Delta \varepsilon_{S}}-\overline{\Delta \varepsilon_{0}}\right]=\gamma
\end{aligned}
$$

However, it is not obvious that the variance of the two estimators will be the same:

$\operatorname{Var}\left[\hat{\gamma}_{1}\right]=\operatorname{Var}\left[\gamma+\overline{\Delta \varepsilon_{S}}-\overline{\Delta \varepsilon_{1}}\right]=\operatorname{Var}\left[\overline{\Delta \varepsilon_{S}}\right]+\operatorname{Var}\left[\overline{\Delta \varepsilon_{1}}\right]-2 \cdot \operatorname{Cov}\left(\overline{\Delta \varepsilon_{S}}, \overline{\operatorname{\Delta E} \Phi}\right)$
$\operatorname{Var}\left[\hat{\gamma}_{0}\right]=\operatorname{Var}\left[\gamma+\overline{\Delta \varepsilon_{S}}-\overline{\Delta \varepsilon_{0}}\right]=\operatorname{Var}\left[\overline{\Delta \varepsilon_{S}}\right]+\operatorname{Var}\left[\overline{\Delta \varepsilon_{0}}\right]-2 \cdot \operatorname{Cov}\left(\overline{\Delta \varepsilon_{S}}, \overline{\overline{\Delta 1} 8}\right)$

Clearly, if $\operatorname{Var}\left[\overline{\Delta \varepsilon_{S}}\right]=\operatorname{Var}\left[\overline{\Delta \varepsilon_{0}}\right]=\operatorname{Var}\left[\overline{\Delta \varepsilon_{1}}\right]$ (i.e. homoskedasticity across the three groups), the variance of these two estimators will be equal. However, if there exists Heteroscedasticity in the error term across the three groups, four terms that will determine which is the lower variance estimator: $\operatorname{Var}\left[\overline{\Delta \varepsilon_{1}}\right]$, $\operatorname{Var}\left[\overline{\Delta \varepsilon_{0}}\right], \operatorname{Cov}\left(\overline{\Delta \varepsilon_{S}}, \overline{\Delta \varepsilon_{1}}\right)$ and $\operatorname{Cov}\left(\overline{\Delta \varepsilon_{S}}, \overline{\Delta \varepsilon_{0}}\right)$. It is not obvious which term is bigger: $\operatorname{Var}\left[\overline{\Delta \varepsilon_{1}}\right], \operatorname{Var}\left[\overline{\Delta \varepsilon_{0}}\right]$-that is, for whom is there a greater unexplained variation in labor market outcomes, those who were undocumented in both 
periods, or those who were documented in both periods. However, it seems reasonable to assume $\operatorname{Cov}\left(\overline{\Delta \varepsilon_{S}}, \overline{\Delta \varepsilon_{1}}\right)<\operatorname{Cov}\left(\overline{\Delta \varepsilon_{S}}, \overline{\Delta \varepsilon_{0}}\right)$. As a whole, migrants who were undocumented in one period were probably more like those who were undocumented in both periods than they were like those who had papers in both periods. Thus, the labor market shocks faced by the "switchers" were probably much more similar to those faced by the "always-undocumented-non-switchers" than to the "always-documented-non-switchers."

Put another way, suppose that the econometrician was able to intervene in the immigrant process in order to conduct randomized trials used to estimate the effect of legal status on earnings. It is clear that the ideal experiment would involve a set of undocumented migrants, some of whom would be randomly selected to receive green cards, while others would not. Here, the control group would be those who were undocumented in both periods and the treatment group would be those who move from undocumented status to legal status The treatment group represents exactly what policy reforms under consideration propose to do: switch the legal status of some undocumented migrants.

By identifying the effect of legal status primarily off differences between those who obtained legal status and those who remained undocumented-as opposed to those who were always documented-we believe that our paper makes a contribution to this literature. If our results differ significantly from prior studies, this suggests that "always-docuentetd-non-switchers" may not be an appropriate control group. If our results do not differ, prior results look even stronger. Either way, the issue of finding an appropriate control group is important enough that in order to definitively answer the research question posed here, it seems necessary to obtain estimates using both potential control groups. 


\subsection{Instrumental Variables}

Here, we relax the assumption that changes in legal status are uncorrelated with time invariant characteristics $\left(E\left[\Delta \varepsilon_{i} \mid x_{i}, L_{i}\right]=0\right)$. Instead, we focus on finding a variable that reflects $z_{i}$ a source of exogenous vacation in legal status that is orthogonal to the time varying labor market shocks to individuals: some variable for which $\left(E\left[\Delta \varepsilon_{i} \mid z_{i}, L_{i}\right]=0\right)$.

To obtain this variation, we turn our attention to the different channels through which individuals in our data set might have obtained legal status. These include sponsorship from employers, family, or U.S. government amnesty programs.

Sponsorship by employers is likely correlated with the unobserved characteristics of the migrant: the more productive the worker, the more likely the employer would be willing to expend resources to procure them a visa to be hired. While our fixed effects estimation should alleviate some of this spurious correlation between legal status and earnings, it is still likely that time varying shocks to a migrants unobservables/productive could still be rewarded with changes in legal status.

At first blush, family sponsorship seems to be a good candidate for exogenous variation. However, migrants who have enough family connections to the United States to obtain a green card would likely also be able to use these connections to serve as a network to improve their match in the U.S. labor market. Again, the use of panel data should partially mitigate this problem, but it is unclear that there would be no correlation between family networks and time varying shocks.

U.S. government programs that granted amnesty to those who had been in the country without documents do provide us with a good source of variation in legal status with which we should be able to obtain consistent estimates 
of the causal effect of legal status on labor market outcomes. Specifically, we use the amnesty granted under the 1986 Immigration Reform and Control Act (IRCA). In addition to tightening enforcement along the border between the United States and Mexico and imposing new sanction upon employers found to be hiring undocumented workers, IRCA also granted a path to legal status for two distinct groups of migrants.

The first group eligible for permanent resident status under IRCA were those individuals who could prove that they had entered the United States before January 1st, 1982. The second set of workers, legalized under the Special Agricultural Workers program (SAW) were given much more flexible treatment in terms of date of entry to the U.S. and duration of residency, but had to have been employed in agricultural work before the passage of IRCA.

In the technical sense of the word, these legalization procedures were clearly exogenous to the migrant; they in no way were a choice variable in the model of the migrants behavior. Econometrically, these programs would give us the variation needed to obtain consitent estimates of the causal effect of legal status on earnings so long as changes in the migrants status that resulted from SAW or IRCA were not correlated with any time specific unobserved shocks that those migrants productivity. In making the case for the validity of this instrument, we note that a number of prior studies have used IRCA as a source of exogenous variation to estimate the effect of legal status on earnings. Here, the primary difference is the control group used.

One possible issue with the use of the IRCA legalizations is the presence of substantial general equilibrium effects: in addition to changing labor market outcomes for individuals obtaining legal status under the program, it is likely that the program affected the labor market as a whole. If this is the case, our estimate at $\gamma$ would not be consistent in the strictest sense. If confounded 
with general equilibrium effects, the estimate of $\gamma$ obtained in our regressions could not be used to answer the following question: if we randomly selected one migrant in the United States and gave them a green card, by how much (if at all) would their earnings increase? However, the primary policy motivation for this paper are proposals that enact another IRCA like "amnesty programs". While the costs borne by migrants to obtain legal status would likely be much stiffer than in 1986, the end result would be very similar: a large number of migrants would go from being undocumented to documented. This number would be large enough to impact the labor market as a whole. Thus, in assessing these policy proposals, it is fairer to say that confounding the effect on the individual with the general equilibrium is necessary rather than problematic.

\section{Data}

\subsection{MMP}

We use data from the Mexican Migration Project-114, a demographic survey of households in 114 communities throughout Mexico. Since its inception over 25 years ago, the MMP has periodically conducted interviews of a randomly selected set of households in pre-selected comminutes. The comminutes are not randomly selected-there is a strong bias towards selecting comminutes for which migration is more prevalent than in the country as a whole, thus allowing large enough sample sizes to effectively study Mexican Migration.

The MMP includes a retrospective migration history survey. Detailed questions are asked about the migrants first and last (most recent) migration. The respondents provide information about labor market earnings as well as legal status during these migrations. MMP surveys are often conducted during either the Christmas holidays or around feasts for the patron saint of the community. 
During these times, migrants are more likely to return to their communities for significant periods of time. Data anout migrants who are not present in the community at the time of the interview, however, is often still included in the sample, as other family members can provide this information to the surveyors.

From the MMP 114, we select a sample of individuals who embarked on at least one migration spell between 1966 and 2005. We choose to eliminate observations from prior to 1966 because during that period, the Bracero guest worker program was still in place; the end of this program is often treated as a structural break in migration patterns. From this sample, we include all migrants for whom we have key demographic and migration event history, such as education levels, age, as the year of the migration, the type of documents used, and hourly wages during the migration spell. We also omit all observations for which the hourly wage was coded at more than $\$ 50$ per hour as we believe these are mis-codes in the data. We then convert all wage data into 2007 dollars.

In Table 1, we give summary statistics on the legal status of the individuals in our sample. During the first migration, we observe nearly 4600 individuals who we classify as undocumented. These include those who entered the country with no documents, false documents, as well as those who have entered on a nonworking visa. Our "documented" category includes green card holders ("Legal Resident"), individuals on temporary work visas, and U.S. citizens. In all, we observe 445 migrants with documents in their first migration.

In Table 2, we present the same statistics as in Table 1 , but only for the subset of observations for which we observe labor market outcomes in two different migrations. While the total size of the sample is cut by more than half, the proportion of document and undocumented migrants stays relatively stable, between 7 and 9 percent in both of the samples.

Using this same set of individuals, Table 3 gives legal status in the most 
recent migration. Between the first and last migrations, the share of migrants who possessed documents climbed from 7 percent to over 40 percent. To explore how this transition to legal status went about, in Table 4 we present a cross-tab of legal status in the two migrations and in Table 5 we use this data to create a Markov transition matrix.

In the first row, we see that the discussion of the econometric model above missed one small category of people: those who have gone from documented to undocumented. In total, 4 individuals who had temporary work visas in their first migration returned to the U.S. as undocumented migrants by their last migration. Two individuals even appear to have lost their green cards, and one individual lost his citizenship! A future draft of the paper will try to more adequately explain the presence of these observations or check for the robustness of the results to the omissions of the observations.

Tables 6 and 7 present transition between legal states using our simplified binary "undocumented/documented" variable. We see that nearly $40 \%$ of undocumented migrants have transitioned to legal status between the two observed migrations. Note because this is panel data, that statistic does not reflect any kind of selection effect or survivor bias. However, because not all individuals in the sample have migrated in two periods, there is obviously a selection problem into who chooses to migrate more than once which is most likely a function of legal status. In other words, we are not contenting that $40 \%$ of the population of all undocumented migrations to the United States obtain legal status.

To test for selection into undertaking more than one migration spell, in Table 8 we test whether or not legal status in the first migration had any effect on whether or not an individual is observed undertaking more than one migration. Not surprisingly, initial conditions matter. Surprisingly, it is the undocumented who are more likely to be repeat migrations. There are several possible expla- 
nations for this. One explanation is that migrants move to the United States in order to reach a specific savings target (Carrion 2007), and those who are undocumented have lower labor market earnings and must undertake more migrations in order to reach this target. Another explanation could be that individuals in the survey who started with legal status have more or less permanently relocated to the United States and are a single long migration Further study of the data will attempt to test these two competing hypothesis.

We present summary statistics on individuals during their first migration in Table 9. These statistics are presented for all migrants, migrants for whom we have observed only one migration spell, and repeat migrations For each of these groups, we subdivided the sample into documented and undocumented migrations. Two striking observations from this table are the earnings and gender gap between documented and undocumented migrants. For each group, documented migrants were more than $50 \%$ more likely to be female, and documented migrants also earned on average wages that were $\$ 5$ an hour higher than those earned by undocumented migrants.

In Table 10, we present summary statistics on the last migration, and in Table 11 we present summary statistics on the change in the values of the time varying variables between the two migrations Note that while real wages remained relatively constant for those who did not receive documents, they grew by $\$ .5$ per hour for those who did. This, however, might be confounded by the fact that individuals who received documents on average gained more than twice as much experience in the U.S. labor markets between these two observations than those who did not receive documents. 


\section{Results}

\subsection{Cross-Sectional Analysis}

We begin our formal examination of the data with Table 12, where we present results from an OLS regression of legal status in the first migration on wages. Legal status is estimated to be positive and significant, even after conditioning upon gender, education, experience in the U.S. labor market, total experience, the square of the two experience variables, and the calendar year of the observation. Restricting our analysis only the repeat migrants, we find in Table 13 a similar set of results from the OLS regression. Both estimates of the returns to legal status are positive and significant and on order of around 25 to $40 \log$ points.

We then expand our analysis to the second cross section of the data. In Table 14, we find a positive and significant effect of legal status on wages in the last migration. The magnitude of the effect, however, is around 9 log points, much smaller than that of the effect in the first migration. This may indicate that legal status is much less valuable for experienced migrants who are more likely to have ties to a network that can help them navigate the informal economy. However, it might also indicate that both estimates are biased estimates of the true effect, and the bias differs between the two regressions.

In Table 15, we address this possible bias through the use of fixed effects. After conditioning upon the calendar years of the first and last migrations (which should control for macro shocks) and the change in all time varying variables from the prior models, we find a positive and significant result of around $12 \mathrm{log}$ points.

Finally, we test for the presence of heterogenous effects between the two migrations. If the effect of legal status on wages differs between the first and last migrations, our model should be represented as below: 


$$
\begin{aligned}
y_{i 1} & =X_{i 1} \beta+L_{i 1} \gamma_{1}+e_{i 1} \\
y_{i 2} & =X_{i 2} \beta+L_{i 2} \gamma_{2}+e_{i 2} \\
\Delta y_{i} & =\Delta x_{i} \beta+L_{1 i} \gamma_{1}-L_{2 i} \gamma_{2}+\Delta \varepsilon_{i}
\end{aligned}
$$

In other words, instead of regressing changes in wages on change in legal status, we regress changes in wages on two separate variables: legal status in the first period, and legal status in the last period. We do find evidence of a higher return in the last period than the first period, though the P-Value on the test of the equivalence of the two effects is only .20, thus we are not able to reject the null hypothesis that the effects are the same in the first and last migrations.

\subsection{Instrumental Variables Analysis}

We now turn our attention to the instrumental variable analysis. In Table 17, we tabulate the year in which repeat migrants obtained legal status. The impact of the 1986 IRCA can be clearly seen in the spike of legalizations occurring after its passage. In total, we observe more legalizations occurring in 1987 and 1988 than in all other years combined. For nearly a third of migrants who received

legal status in our data set, the migrants do not report the year in which they received their green card. This issue with the data motivates the proxy variable for legalization under IRCA described below.

For about $70 \%$ of the legalized repeat migrants, we also have self-reported data on the source of the legalization. While $30 \%$ of these migrants reported receiving their legal status as a result of IRCA, even more (35\%) of migrants reported receiving it from the concurrent Special Agricultural Workers program.

From the above information, we construct a number of instrumental vari- 
ables. In order to capture the variation in legal status that stemmed from IRCA, we create one instrument that is equal to 1 if the migrant reported being legalized under IRCA, and 0 otherwise. We create a separate instrument that measures whether the migrant was likely eligible for IRCA. This variable is equal to 1 if the first migration that we observe took place before 1982, the last migration took place after 1986, and the migrant did not work as an agricultural worker during their first migration. Given the measurement error in the data, this may better account for the set of migrants who received legal status from IRCA. Additionally, even for those who did not receive legalization directly from IRCA, it may pick up the indirect effects of IRCA on the likelihood of receiving legal status for migrants who had moved to the United States around the time that IRCA was passed (namely, receiving legal status after being sponsored by a family member who had been legalized under IRCA). Finally, we create a third instrument from IRCA: the union of the two pervious instruments.

Our instruments from variation in the data caused by SAW are constructed in a similar manner. First, we have a self-reported SAW variable. Second, we use a "SAW eligible" variable. This variable takes on a value of 1 if the migrant is observed in the United States after 1986 in their last migration, and reported working in agriculture during their first migration. We do not restrict the date of the first migration to be before a specific year, as the amnesty provision for agricultural workers was much less restrictive, and prior research suggests that many migrants who received legal status under SAW migrated to the United States even after the legislation had been passed. Finally, we also create a variable equal to the union of self reported legalization under SAW and our proxy for SAW eligibility.

In Table 21, we report our results from Two-Stage-Least-Squares (2SLS) estimations using each of our three IRCA instruments. Each instrument is 
positive and significant in the first stage-which must be the case as instead of using exogenous shifters of legal status we are in essence selecting a subset of legalized for our exogenous variation.

In each of the final stages, we find positive and significant estimates of the effect of legal status on earnings. Of some surprise to us is that the IV estimates are greater in magnitude than the OLS estimates, suggesting that the OLS estimates were biased downwards. The IV estimates range between 21 and 27 log points, depending on the instrument used.

The results obtained from the 2SLS regressions on the SAW instruments present a much different picture. While the instruments are positive and significant, just as the IRCA instruments are, we find now evidence of a causal relationship between earnings and legal status.

To further explore how effects differed by type of worker, in Table 23 we run a 2SLS model with two endogenous variables in the wage determination equation: legal status, and legal status interacted with an indicator variable for agricultural workers. In the OLS regression on changes of these variables on changes in wages, we find the overall effect of legal status to be positive and significant. The interacted term in negative and marginally significant. Once we instrument, we find the overall effect of legal status on workers earnings to be a positive and significant $18 \log$ points, while the interacted term is negative and significant. In fact, we cannot reject the null hypothesis that receiving legal status has no effect on wages for agricultural workers.

The sharp difference of the effect of legal status on workers in these two different occupations could suggest a number of things about how labor markets work for migrants. It is possible that employers are able to exert market power over undocumented non-agricultural workers, but not over undoucmented-agricultural workers (this would lead to an increase in the wages of non-agricultural workers 
when receiving legal status, but not to agricultural workers). It is also possible that employers are able to exert market power over all agricultural workers, and to only undocumented non-agricultural workers. Additionally, it is possible that the non-agricultural workers possessed skills that, once coupled with legal status, allowed these workers to obtain better labor market outcomes by tranitioning from unskilled labor markets to semi-skilled labor markets. Future research will attempt to address the mechanism for legal status increasing labor market outcomes, as well as the reasons why this effect does not seem to be present for agricultural workers.

\section{Conclusion}

In this paper we address the question of legal status affects the labor market outcomes of workers. In contrast to the literature, we are able to use changes in the wages of undocumented migrants as a control for changes in the wages of those who have received legal status. Like others, we use the 1986 Immigration Control and Reform Act (IRCA), which granted legal status to hundreds of thousands of undocumented migrants, as an exogenous source of variation in legal status. Surprisingly, when using IRCA as an instrumental variable, we obtain even higher estimates of the effect of legal status on earnings than we do when using fixed effects alone. The IV estimates are on the order of 22 to $27 \log$ points, while the fixed effects estimates are closer to $12 \log$ points. Even our smallest estimates are near the upper bound of previous estimates in the literature.

To account for possible heterogenous effects of legal status on earnings, we examine how the effect differs between agricultural and non-agricultral workers. When we use variation in legal status stemming from IRCA, we find positive and significant effects. However, when we use only variation in legal status that 
is derived from legalizations occurring from the Special Agricultural Workers Program (SAW), we find no evidence of an effect of legal status on earnings. Future work will seek to identify the cause of this discrepancy, and to explore what this tells us about how labor markets in general work.

How a mass legalization of undocumented workers would affect labor markets is a central issue of contention in the current debate on immigration reform. Our findings that legalized workers benefit significantly from obtaining legal status are relevant to the policy debate in a number of ways. To begin, the magnitude of the effect suggests either that non-agricultural workers are able to find better matches in employment post legalization, or that workers are able freed from monopsonistic relationships with their employers that may have existed while they were undocumented. In either case, the results suggest that a mass legalization of this migrants could result in significant value added to the U.S. labor market. Finally, proponents of a mass legalization choose pursue a pragmatic strategy of legislating a legalization program that, to avoid the stigmatic label of "amnesty", would also include a relatively large "fine" attached as a price paid by migrants for obtaining the green card. Our results suggest that migrants should be willing to pay a rather large price to obtain legal status-possibly as high as $10 \%$ of the present value of their current labor market earnings. 


\section{References}

Amuedo-Dorantes, Catalina, Cynthia Bansak, and Steven Raphael. 2007. "The Impact of Amnesty on Labor Market Outcommes: A Panel Study Using the Legalized Population Survey."

Borjas, George J. 1985. "Assimilation, Changes in Cohort Quality, and the Earnings of Immigrants." Journal of Labor Economics, 3 (4): 463-489.

Bratsberg, Brent, James F. Ragan Jr., and Zafar M. Nasir. 2002. "The Effect of Naturalization on Wage Growth: A Panel Study of Young Immigrants." Journal of Labor Economics, 20 (3).

Chiswick, Barry R. 1978. "The Effect of Americanization on the Earnings of Foreign-born Men." The Journal of Political Economy, 86 (5): 897-921.

Gass-Kandilov, Amy. 2007. "The Value of a Green Card:Immigrant Wage Increases Following Adjustment to U.S. Permanent Residence."

Kaushal, Neeraj. 2006. "Amnesty Programs and the Labor Market for Undocumented Workers." The Journal of Human Resources, 41 (3): 631-647.

Kossoudji, Sherrie A. and Deborah Cobb-Clark. 2002. "Coming out of the Shadows: Learning about Legal Status and Wages from the Legalized Population." Journal of Labor Economics, 20 (3): 598-628.

Rivera-Batiz, Francisco. 1999. "Undocumented workers in the labor market: An analysis of the earnings of legal and illegal Mexican immigrants in the United States." Journal of Population Economics, 12 (1): 91-116. 
Table 1: Documentation Used on First Migration (all migrants)

\begin{tabular}{lcc|}
\hline \hline \multicolumn{1}{c}{ MMP Category } & "Undocumented" & "Documented" \\
\hline 1 Legal Resident & - & 373 \\
2 Bracero & - & - \\
3 Contract-H2A (agricultural) & - & 18 \\
4 Temporary: Worker & - & 39 \\
5 Temporary: Tourist/Visitor & 286 & \\
6 Citizen & - & 15 \\
7 Silva Letter & - & - \\
8 Undocumented or false documents & 4,312 & - \\
9 Refugee/asylee & - & - \\
\hline Total & 4598 & 445 \\
\hline
\end{tabular}


Table 2: Documentation Used on First Migration (reapeat migrants)

\begin{tabular}{lcc}
\hline \hline \multicolumn{1}{c}{ MMP Category } & "Undocumented" & "Documented" \\
\hline 1 Legal Resident & - & 122 \\
2 Bracero & - & - \\
3 Contract-H2A (agricultural) & - & 8 \\
4 Temporary: Worker & - & 13 \\
5 Temporary: Tourist/Visitor & 98 & - \\
6 Citizen & - & 1 \\
7 Silva Letter & - & - \\
8 Undocumented or false documents & 1870 & 0 \\
9 Refugee/asylee & - & - \\
\hline Total & 1968 & 144 \\
\hline
\end{tabular}


Table 3: Documentation Used on Last Migration (reapeat migrants)

\begin{tabular}{clcc}
\hline \hline \multicolumn{1}{c}{ MMP Category } & "Undocumented" & "Documented" \\
\hline 1 & Legal Resident & - & 805 \\
2 & Bracero & - & - \\
3 & Contract-H2A (agricultural) & - & 23 \\
4 & Temporary: Worker & - & 17 \\
5 & Temporary: Tourist/Visitor & 73 & - \\
6 & Citizen & - & 22 \\
7 & Silva Letter & - & - \\
& & & \\
8 & Undocumented or false documents & 1162 & 0 \\
9 & Refugee/asylee & - & - \\
9999 & Missing & 10 & - \\
\hline$\quad$ Total & 1245 & 867 \\
\hline
\end{tabular}

not that it is not just selection because not just the proportion but also the absolute number of legal residents goes up 
Table 4: Cross Tab on Status (repeat migrants)

\begin{tabular}{|c|c|c|c|c|c|c|c|c|}
\hline First Migration/Last Migration & Legal Resident & $\begin{array}{l}\text { Contract-H2A } \\
\text { (agricultural) }\end{array}$ & $\begin{array}{l}\text { Temporary: } \\
\text { Worker }\end{array}$ & $\begin{array}{l}\text { Temporary: } \\
\text { Tourist/Visitor }\end{array}$ & Citizen & $\begin{array}{l}\text { Undocumented or } \\
\text { False documents }\end{array}$ & Missing & Total \\
\hline Legal Resident & 119 & 0 & 0 & 1 & 1 & 1 & 0 & 122 \\
\hline Contract-H2A (agricultural) & 0 & 7 & 0 & 0 & 0 & 1 & 0 & 8 \\
\hline Temporary: Worker & 1 & 1 & 8 & 1 & 0 & 2 & 0 & 13 \\
\hline Temporary: Tourist/Visitor & 36 & 0 & 0 & 49 & 2 & 11 & 0 & 98 \\
\hline Citizen & 0 & 0 & 0 & 0 & 0 & 1 & 0 & 1 \\
\hline Undocumented or false documents & 649 & 15 & 9 & 22 & 19 & 1146 & 10 & 1870 \\
\hline Total & 805 & 23 & 17 & 73 & 22 & 1162 & 10 & 2112 \\
\hline
\end{tabular}

talk about how people keep saying that undocumetned need to get in line behind everyone else and how there are paths to ctiizen ship and visas now; then look at how many people have those visas here 
Table 5: Markov Transition Matrix on Status (repeat migrants)

\begin{tabular}{|c|c|c|c|c|c|c|c|}
\hline First Migration/Last Migration & Legal Resident & $\begin{array}{l}\text { Contract-H2A } \\
\text { (agricultural) }\end{array}$ & $\begin{array}{l}\text { Temporary: } \\
\text { Worker }\end{array}$ & $\begin{array}{l}\text { Temporary: } \\
\text { Tourist/Visitor }\end{array}$ & Citizen & $\begin{array}{l}\text { Undocumented or } \\
\text { False documents }\end{array}$ & Missing \\
\hline Legal Resident & $97.54 \%$ & $0.00 \%$ & $0.00 \%$ & $0.82 \%$ & $0.82 \%$ & $0.82 \%$ & $0.00 \%$ \\
\hline Contract-H2A (agricultural) & $0.00 \%$ & $87.50 \%$ & $0.00 \%$ & $0.00 \%$ & $0.00 \%$ & $12.50 \%$ & $0.00 \%$ \\
\hline Temporary: Worker & $7.69 \%$ & $7.69 \%$ & $61.54 \%$ & $7.69 \%$ & $0.00 \%$ & $15.38 \%$ & $0.00 \%$ \\
\hline Temporary: Tourist/Visitor & $36.73 \%$ & $0.00 \%$ & $0.00 \%$ & $50.00 \%$ & $2.04 \%$ & $11.22 \%$ & $0.00 \%$ \\
\hline Citizen & $0.00 \%$ & $0.00 \%$ & $0.00 \%$ & $0.00 \%$ & $0.00 \%$ & $100.00 \%$ & $0.00 \%$ \\
\hline Undocumented or false documents & $34.71 \%$ & $0.80 \%$ & $0.48 \%$ & $1.18 \%$ & $1.02 \%$ & $61.28 \%$ & $0.53 \%$ \\
\hline
\end{tabular}


Table 6: Cross-Tab of Legal Status

\begin{tabular}{lcc}
\hline \hline First/Last & Undocumented & Documented \\
\hline Undocumented & 1300 & 734 \\
Documented & 7 & 144
\end{tabular}

Table 7: Markov Transition Matrix

\begin{tabular}{lrc}
\hline \hline First/Last & One-Time & Repeat \\
\hline Undocumented & $63.91 \%$ & $36.09 \%$ \\
Documented & $4.64 \%$ & $95.36 \%$
\end{tabular}


Table 8: Selection in Return Migration

\begin{tabular}{lrr}
\hline \hline & One-Time & Repeat \\
\hline Undocumented & $89.51 \%$ & $92.95 \%$ \\
Documented & $10.49 \%$ & $7.05 \%$ \\
\hline Chi2 & 18.5855 & \\
$P$ & 0 & \\
\hline
\end{tabular}


Table 9: Summary Statistics on Migrants in First Migration

\begin{tabular}{|c|c|c|c|c|c|c|c|}
\hline \multirow{2}{*}{$\begin{array}{c}\begin{array}{c}\text { Repeat/One Time } \\
\text { Migrants }\end{array} \\
\text { All }\end{array}$} & \multirow{2}{*}{$\begin{array}{c}\text { Legal Status } \\
\text { Documented }\end{array}$} & Variable & Mean & $\mathbf{N}$ & Min & \multicolumn{2}{|c|}{ Max } \\
\hline & & Age & 24.02 & 8.64 & 445 & 15.0 & 59.0 \\
\hline & & Wage & 14.09 & 8.94 & 445 & 1.7 & 47.7 \\
\hline & & Year & 1982.62 & 9.84 & 445 & 1965.0 & 2004.0 \\
\hline & & Female & 0.33 & 0.47 & 445 & 0.0 & 1.0 \\
\hline & & Education & 7.49 & 3.83 & 445 & 0.0 & 18.0 \\
\hline & & Duration & 73.85 & 88.29 & 445 & 1.0 & 450.0 \\
\hline & Undocumented & Age & 24.03 & 7.90 & 4598 & 15.0 & 62.0 \\
\hline & & Wage & 9.57 & 5.72 & 4598 & 0.4 & 49.6 \\
\hline & & Year & 1984.07 & 8.42 & 4598 & 1965.0 & 2005.0 \\
\hline & & Female & 0.17 & 0.37 & 4598 & 0.0 & 1.0 \\
\hline & & Education & 6.50 & 3.61 & 4598 & 0.0 & 28.0 \\
\hline & & Duration & 34.73 & 51.41 & 4598 & 1.0 & 438.0 \\
\hline \multirow[t]{12}{*}{ One-Time } & Documented & Age & 24.72 & 8.67 & 273 & 15.0 & 59.0 \\
\hline & & Wage & 14.56 & 9.67 & 273 & 2.0 & 47.7 \\
\hline & & Year & 1984.30 & 9.52 & 273 & 1965.0 & 2004.0 \\
\hline & & Female & 0.34 & 0.47 & 273 & 0.0 & 1.0 \\
\hline & & Education & 7.67 & 3.97 & 273 & 0.0 & 17.0 \\
\hline & & Duration & 106.26 & 95.53 & 273 & 1.0 & 450.0 \\
\hline & Undocumented & Age & 25.17 & 8.57 & 2329 & 15.0 & 62.0 \\
\hline & & Wage & 9.52 & 5.91 & 2329 & 0.5 & 47.7 \\
\hline & & Year & 1986.86 & 8.22 & 2329 & 1965.0 & 2005.0 \\
\hline & & Female & 0.22 & 0.42 & 2329 & 0.0 & 1.0 \\
\hline & & Education & 6.84 & 3.69 & 2329 & 0.0 & 24.0 \\
\hline & & Duration & 47.75 & 64.46 & 2329 & 1.0 & 438.0 \\
\hline \multirow[t]{12}{*}{ Repeat } & Documented & Age & 22.40 & 8.13 & 144 & 15.0 & 56.0 \\
\hline & & Wage & 13.08 & 7.39 & 144 & 1.7 & 38.1 \\
\hline & & Year & 1980.69 & 9.80 & 144 & 1965.0 & 2003.0 \\
\hline & & Female & 0.27 & 0.45 & 144 & 0.0 & 1.0 \\
\hline & & Education & 7.59 & 3.51 & 144 & 0.0 & 18.0 \\
\hline & & Duration & 18.46 & 33.55 & 144 & 1.0 & 252.0 \\
\hline & Undocumented & Age & 22.86 & 6.93 & 1968 & 15.0 & 60.0 \\
\hline & & Wage & 9.64 & 5.43 & 1968 & 0.5 & 49.6 \\
\hline & & Year & 1981.25 & 7.60 & 1968 & 1965.0 & 2002.0 \\
\hline & & Female & 0.10 & 0.30 & 1968 & 0.0 & 1.0 \\
\hline & & Education & 6.14 & 3.52 & 1968 & 0.0 & 28.0 \\
\hline & & Duration & 21.15 & 26.95 & 1968 & 1.0 & 300.0 \\
\hline
\end{tabular}

When looking at last show gap between migrations 
Table 10: Summary Statistics on Migrants in Last Migration

\begin{tabular}{clrrrrr}
\hline \hline & & & & & & \\
Legal Status & Variable & \multicolumn{1}{c}{ Mean } & SD & \multicolumn{2}{c}{ N } & \multicolumn{2}{c}{ Min } & \multicolumn{2}{c}{ Max } \\
\hline \hline Documented & Age & 32.89 & 8.54 & 867 & 16.0 & 63.0 \\
& Wage & 10.88 & 5.72 & 867 & 1.4 & 39.7 \\
& Year & 1990.92 & 5.25 & 867 & 1969.0 & 2005.0 \\
& Sex & 0.13 & 0.34 & 867 & 0.0 & 1.0 \\
& Education & 6.66 & 3.62 & 867 & 0.0 & 28.0 \\
& Duration & 25.62 & 40.56 & 867 & 1.0 & 300.0 \\
Undocumented & Age & 30.06 & 8.58 & 1245 & 16.0 & 64.0 \\
& Wage & 9.43 & 4.97 & 1245 & 1.1 & 38.5 \\
& Year & 1988.68 & 7.15 & 1245 & 1968.0 & 2005.0 \\
& Sex & 0.09 & 0.29 & 1245 & 0.0 & 1.0 \\
& Education & 5.95 & 3.44 & 1245 & 0.0 & 19.0 \\
& Duration & 21.82 & 34.88 & 1245 & 1.0 & 306.0
\end{tabular}


Table 11: Summary Statistics on Changes Between Migrations

\begin{tabular}{|c|c|c|c|c|c|c|c|c|}
\hline Legal Status & Variable & Mean & SD & $\mathrm{N}$ & & Min & \multicolumn{2}{|c|}{ Max } \\
\hline Received & "Wage & 0.51 & & 7.20 & 730 & & $\overline{-35.4}$ & $\overline{\overline{33.4}}$ \\
\hline \multirow[t]{2}{*}{ Documents } & Years & 11.21 & & 6.41 & 730 & & 1.0 & 31.0 \\
\hline & US Experience & 85.65 & & 65.31 & 730 & & 2.0 & 354.0 \\
\hline Did not Receive & Wage & -0.04 & & 5.87 & 1375 & & -35.3 & 31.8 \\
\hline \multirow{2}{*}{ Documents } & Years & 6.90 & & 5.41 & 1375 & & 1.0 & 30.0 \\
\hline & US Experience & 36.41 & & 41.12 & 1375 & & -86.0 & 324.0 \\
\hline \multirow[t]{3}{*}{ Lost Documents } & Wage & -0.35 & & 6.84 & 7 & & -15.2 & 4.6 \\
\hline & Years & 6.29 & & 7.93 & 7 & & 1.0 & 24.0 \\
\hline & US Experience & 23.71 & & 19.03 & 7 & & 3.0 & 60.0 \\
\hline
\end{tabular}


Table 12: OLS Results of Regression on log Wages (all migrants in first migration)

\begin{tabular}{|c|c|c|c|c|c|c|c|c|c|c|c|c|}
\hline \multirow[b]{2}{*}{ Variable } & \multicolumn{2}{|c|}{ Model 1} & \multicolumn{2}{|c|}{ Model 2} & \multicolumn{2}{|c|}{ Model 3} & \multicolumn{2}{|c|}{ Model 4} & \multicolumn{2}{|c|}{ Model 5} & \multicolumn{2}{|c|}{ Model 6} \\
\hline & Beta & $\mathbf{T}$ & Beta & $\mathbf{T}$ & Beta & $\mathbf{T}$ & Beta & $\mathbf{T}$ & Beta & $\mathbf{T}$ & Beta & $\mathbf{T}$ \\
\hline Legal Status & 0.356 & 9.19 & 0.382 & 9.43 & 0.383 & 9.33 & 0.388 & 9.72 & 0.296 & 5.3 & 0.243 & $\overline{6.04}$ \\
\hline Female & & & -0.156 & -5.29 & -0.156 & -5.29 & -0.149 & -5.10 & -0.200 & -5.98 & -0.183 & -6.42 \\
\hline Education & & & & & -0.001 & -0.37 & -0.008 & -2.33 & -0.007 & -1.89 & 0.012 & 3.82 \\
\hline Experience & & & & & & & -0.001 & -0.24 & 0.001 & 0.41 & 0.002 & 0.79 \\
\hline Experience $^{\wedge} 2$ & & & & & & & 0.000 & -2.30 & 0.000 & -2.38 & 0.000 & -1.68 \\
\hline US Experience & & & & & & & & & 0.003 & 6.17 & 0.004 & 8.34 \\
\hline US Experience^^2 & & & & & & & & & 0.000 & -1.64 & 0.000 & -4.01 \\
\hline Entry Cohort Controls & & & & & & & & & & & $\underline{x}$ & \\
\hline Constant Term & 2.12 & 99.12 & 2.14 & 100.80 & 2.15 & 71.18 & 2.24 & 44.71 & 2.112628 & 41.05 & 2.14 & 10.28 \\
\hline $\mathrm{N}$ & 50 & & 50 & & 504 & & 504 & & 5043 & & 50 & \\
\hline R-squared & 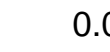 & & 0.0 & & 0.0 & & 0.0 & & 0.12 & & 0.2 & \\
\hline standard errors clustered & unity & & & & & & & & & & & \\
\hline
\end{tabular}


Table 13: OLS Results of Regression on log Wages (repeat migrants in first migration)

\begin{tabular}{|c|c|c|c|c|c|c|c|c|c|c|c|c|}
\hline \multirow[b]{2}{*}{ Variable } & \multicolumn{2}{|c|}{ Model 1} & \multicolumn{2}{|c|}{ Model 2} & \multicolumn{2}{|c|}{ Model 3} & \multicolumn{2}{|c|}{ Model 4} & \multicolumn{2}{|c|}{ Model 5} & \multicolumn{2}{|c|}{ Model 6} \\
\hline & Beta & $\mathbf{T}$ & Beta & $\mathbf{T}$ & Beta & $\mathbf{T}$ & Beta & $\mathbf{T}$ & Beta & $\mathbf{T}$ & Beta & $\mathbf{T}$ \\
\hline Legal Status & 0.290 & 4.18 & 0.314 & 4.29 & 0.319 & 4.19 & 0.328 & 4.54 & 0.346 & 4.21 & 0.275 & 4.42 \\
\hline Sex & & & -0.141 & -2.03 & -0.140 & -2.04 & -0.134 & -1.94 & -0.166 & -2.23 & -0.166 & -2.53 \\
\hline Education & & & & & -0.003 & -0.63 & -0.009 & -1.4 & -0.009 & -1.41 & 0.015 & 2.5 \\
\hline Experience & & & & & & & 0.003 & 0.62 & 0.004 & 0.95 & 0.006 & 1.43 \\
\hline Experience $^{\wedge} 2$ & & & & & & & 0.000 & -2.52 & 0.000 & -2.57 & 0.000 & -2.18 \\
\hline US Experience & & & & & & & & & 0.002 & 2.79 & 0.002 & 3.03 \\
\hline US Experience^2 & & & & & & & & & 0.000 & 3.11 & 0.000 & 1.71 \\
\hline Entry Cohort Controls & & & & & & & & & & & $\underline{x}$ & \\
\hline Constant Term & 2.136 & 75.5 & 2.15 & 79.88 & 2.171 & 53.48 & 2.219 & 31.82 & 2.143174 & 31.25 & 2.327 & 10.93 \\
\hline $\mathrm{N}$ & 21 & & 21 & & 21 & & 21 & & 2112 & & 21 & \\
\hline R-squared & 0. & & & & 0.0 & & 0.0 & & 0.07 & & 0.2 & \\
\hline standard errors cluster & unit & & & & & & & & & & & \\
\hline
\end{tabular}


Table 14: OLS Results of Regression on log Wages (repeat migrants in last migration)

\begin{tabular}{|c|c|c|c|c|c|c|c|c|c|c|c|c|c|c|}
\hline \multirow[b]{2}{*}{ Variable } & \multicolumn{2}{|c|}{ Model 1} & \multicolumn{2}{|c|}{ Model 2} & \multicolumn{2}{|c|}{ Model 3} & \multicolumn{2}{|c|}{ Model 4} & \multicolumn{2}{|c|}{ Model 5} & \multicolumn{2}{|c|}{ Model 6} & \multicolumn{2}{|c|}{ Model 7} \\
\hline & Beta & $\mathbf{T}$ & Beta & $\mathbf{T}$ & Beta & $\mathbf{T}$ & Beta & $\mathbf{T}$ & Beta & $\mathbf{T}$ & Beta & $\mathbf{T}$ & Beta & $\mathbf{T}$ \\
\hline Legal Status & 0.150 & 4.26 & 0.156 & 4.1 & 0.145 & 3.78 & 0.165 & 4.02 & 0.037 & 0.88 & 0.042 & 1.07 & 0.089 & 2.63 \\
\hline Sex & & & -0.139 & -4.09 & -0.142 & -4 & -0.140 & -3.86 & -0.165 & -4.19 & -0.160 & -4.13 & -0.202 & -5.15 \\
\hline Education & & & & & 0.014 & 4.2 & 0.004 & 0.67 & 0.001 & 0.21 & 0.003 & 0.53 & 0.011 & 2.11 \\
\hline Experience & & & & & & & -0.001 & -0.24 & -0.010 & -2.05 & -0.016 & -3.15 & -0.008 & -1.73 \\
\hline Experience^2 & & & & & & & 0.000 & -1.76 & 0.000 & 0.47 & 0.000 & 1.33 & 0.000 & 0.9 \\
\hline US Experience & & & & & & & & & 0.004 & 6.21 & 0.004 & 5.46 & 0.004 & 6.82 \\
\hline US Experience^2 & & & & & & & & & 0.000 & -3.1 & 0.000 & -3.08 & 0.000 & -4.14 \\
\hline First Entry Cohort Controls & & & & & & & & & & & $\mathrm{X}$ & & $X$ & \\
\hline Last Entry Cohort Controls & & & & & & & & & & & & & $\mathrm{X}$ & \\
\hline Constant Term & 2.129 & 74.47 & 2.142 & 74.09 & 2.056 & 52.17 & 2.18714 & 21.67 & 2.133938 & 22.56 & 2.466655 & 10.91 & 2.764448 & 5.39 \\
\hline $\mathrm{N}$ & 211 & & 21 & & 211 & & 2112 & & 2112 & & 2112 & & 2112 & \\
\hline R-squared & 0.0 & & 0. & & 0.0 & & 0.06 & & 0.14 & & 0.18 & & 0.42 & \\
\hline
\end{tabular}


Table 15: FE Results of Regression on Change in log Wages

\begin{tabular}{|c|c|c|c|c|c|c|c|c|c|c|}
\hline \multirow[b]{2}{*}{ Variable } & \multicolumn{2}{|c|}{ Model 1} & \multicolumn{2}{|c|}{ Model 2} & \multicolumn{2}{|c|}{ Model 3} & \multicolumn{2}{|c|}{ Model 4} & \multicolumn{2}{|c|}{ Model 5} \\
\hline & Beta & $\mathbf{T}$ & Beta & $\mathbf{T}$ & Beta & $\mathbf{T}$ & Beta & $\mathbf{T}$ & Beta & $\mathbf{T}$ \\
\hline Change Legal Status & 0.044 & 1.32 & 0.149 & 5.05 & 0.135 & 4.30 & 0.116 & 3.62 & 0.116 & $\overline{3.94}$ \\
\hline Change Exp & & & -0.018 & -3.73 & -0.022 & -3.60 & -0.020 & -3.19 & -0.011 & -1.29 \\
\hline Change $\operatorname{Exp}^{\wedge} 2$ & & & $-2 \mathrm{E}-04$ & -2.07 & 0.000 & -2.01 & 0.000 & -1.62 & 0.000 & -1.59 \\
\hline Change US Exp & & & & & 0.000 & 0.10 & 0.000 & 0.16 & 0.000 & 0.33 \\
\hline Change US Exp^2 & & & & & 0.000 & 0.70 & 0.000 & 0.65 & 0.000 & 0.46 \\
\hline First Entry Cohort Controls & & & & & & & \multirow{2}{*}{\multicolumn{2}{|c|}{ X }} & \multicolumn{2}{|c|}{$x$} \\
\hline Last Entry Cohort Controls & & & & & & & & & \multicolumn{2}{|c|}{$\mathrm{x}$} \\
\hline Constant Term & 0.020 & 0.85 & 0.19 & 8.38 & 0.205 & 9.91 & 0.215 & 1.15 & 0.612 & 1.66 \\
\hline $\mathrm{N}$ & \multicolumn{2}{|c|}{2112} & \multicolumn{2}{|c|}{2112} & \multicolumn{2}{|c|}{2112} & \multicolumn{2}{|c|}{2112} & \multicolumn{2}{|c|}{2112} \\
\hline R-squared & \multicolumn{2}{|c|}{0.00} & \multicolumn{2}{|c|}{0.09} & \multirow{2}{*}{\multicolumn{2}{|c|}{0.09}} & \multirow{2}{*}{\multicolumn{2}{|c|}{0.11}} & \multicolumn{2}{|c|}{0.14} \\
\hline standard errors clustered at comn & level & & & & & & & & & \\
\hline
\end{tabular}


Table 16: Testing for Hetergenous Effects

\begin{tabular}{|c|c|c|c|c|}
\hline \multirow[b]{2}{*}{ Variable } & \multicolumn{2}{|c|}{ Model 5} & \multicolumn{2}{|c|}{ Model 6} \\
\hline & Beta & $\mathbf{T}$ & Beta & $\mathbf{T}$ \\
\hline Change Legal Status & 0.116 & 3.94 & & \\
\hline First Legal Status & & & -0.167 & -3.62 \\
\hline Last Legal Status & & & 0.104 & 3.36 \\
\hline Change Exp & -0.011 & -1.3 & -0.012 & -1.44 \\
\hline Change $\operatorname{Exp}^{\wedge} 2$ & 0.000 & -1.6 & 0.000 & -1.66 \\
\hline Change US Exp & 0.000 & 0.33 & 0.000 & 0.44 \\
\hline Change US Exp^2 & 0.000 & 0.46 & 0.000 & 0.4 \\
\hline First Entry Cohort Controls & \multicolumn{2}{|l|}{$\mathrm{x}$} & \multicolumn{2}{|l|}{$\mathrm{x}$} \\
\hline Last Entry Cohort Controls & \multicolumn{2}{|l|}{$\mathrm{x}$} & \multicolumn{2}{|l|}{$x$} \\
\hline Constant Term & 0.612 & 1.66 & 0.621333 & 1.69 \\
\hline $\mathrm{N}$ & \multicolumn{2}{|c|}{2112} & \multicolumn{2}{|l|}{2112} \\
\hline R-squared & \multicolumn{2}{|c|}{0.14} & \multicolumn{2}{|l|}{0.14} \\
\hline \multicolumn{5}{|c|}{ standard errors clustered at community level } \\
\hline F-Test on First Legal Status=Last L & gal Status & & $1.65(p=.20)$ & \\
\hline
\end{tabular}


Table 17: Year Legal

Status Received

\begin{tabular}{cr}
\hline \hline $\begin{array}{c}\text { Year Legal Status } \\
\text { Received }\end{array}$ & Count \\
\hline 1969 & 3 \\
1970 & 2 \\
1971 & 1 \\
1972 & 1 \\
1973 & 4 \\
1974 & 2 \\
1975 & 6 \\
1976 & 2 \\
1977 & 4 \\
1978 & 7 \\
1979 & 3 \\
1980 & 7 \\
1981 & 6 \\
1982 & 4 \\
1983 & 7 \\
1984 & 6 \\
1985 & 6 \\
1986 & 22 \\
1987 & 130 \\
1988 & 151 \\
1989 & 64 \\
1990 & 31 \\
1991 & 12 \\
1992 & 13 \\
1993 & 3 \\
1994 & 7 \\
1995 & 6 \\
1996 & 3 \\
1997 & 3 \\
1998 & 1 \\
1999 & 12 \\
Unknown & \\
\hline Total & \\
& 630 \\
\hline
\end{tabular}


Table 18: Sponsor of Legalization

\begin{tabular}{|c|c|c|c|}
\hline Sponser & Count & $\%$ of Legalized & $\%$ of Total \\
\hline Spouse & 7 & $0.96 \%$ & $0.32 \%$ \\
\hline Child & 1 & $0.14 \%$ & $0.05 \%$ \\
\hline Parent & 8 & $1.10 \%$ & $0.36 \%$ \\
\hline Sibling & 5 & $0.68 \%$ & $0.23 \%$ \\
\hline IRCA & 217 & $29.73 \%$ & $9.81 \%$ \\
\hline SAW & 257 & $35.21 \%$ & $11.62 \%$ \\
\hline Employer & 13 & $1.78 \%$ & $0.59 \%$ \\
\hline N/A & 222 & $30.41 \%$ & $10.04 \%$ \\
\hline Total & 730 & $100.00 \%$ & \\
\hline
\end{tabular}

508 
Table 19: Legalization and IRCA

\begin{tabular}{clrrr}
\hline \hline & \multicolumn{3}{c}{ IRCA Eligible } \\
\hline \multirow{2}{*}{ IRCA Reported } & No & & 277 & 236 \\
& Yes & & 93 & 124
\end{tabular}


Table 20: Legalization and SAW

\begin{tabular}{ccrc}
\hline \hline & \multicolumn{3}{c}{ IRCA Eligible } \\
\hline \multirow{3}{*}{ No } & \multicolumn{3}{c}{ Yes } \\
IRCA Reported No & & 344 & 129 \\
Yes & & 94 & 163
\end{tabular}


Table 21: IV Results of Regression on Change in log Wages

\begin{tabular}{|c|c|c|c|c|c|c|c|c|c|c|c|c|}
\hline \multirow[b]{3}{*}{ Variable } & \multicolumn{4}{|c|}{ Model 1} & \multicolumn{4}{|c|}{ Model 2} & \multicolumn{4}{|c|}{ Model 3} \\
\hline & \multicolumn{2}{|c|}{ First Stage } & \multicolumn{2}{|c|}{ Final Stage } & \multicolumn{2}{|c|}{ First Stage } & \multicolumn{2}{|c|}{ Final Stage } & \multicolumn{2}{|c|}{ First Stage } & \multicolumn{2}{|c|}{ Final Stage } \\
\hline & Beta & $\mathbf{T}$ & Beta & $\mathbf{T}$ & Beta & $\mathbf{T}$ & Beta & $\mathbf{T}$ & Beta & $\mathbf{T}$ & Beta & $\mathbf{T}$ \\
\hline Change Legal Status & & & 0.221 & 1.98 & & & 0.273 & 2.76 & & & 0.212 & 2.75 \\
\hline IRCA Reported & 0.397 & 12.45 & & & & & & & & & & \\
\hline IRCA Eligible & & & & & 0.530 & 17.9 & & & & & & \\
\hline IRCA Eligible or Reported & & & & & & & & & 0.508 & 17.25 & & \\
\hline Change Exp & 0.009 & 1.55 & -0.012 & -1.58 & 0.009 & 1.48 & -0.013 & -1.63 & 0.008 & 1.41 & -0.012 & -1.58 \\
\hline Change $\operatorname{Exp}^{\wedge} 2$ & 0.000 & -0.51 & 0.000 & -2.01 & 0.000 & -0.2 & 0.000 & -1.98 & 0.000 & 0 & 0.000 & -2.02 \\
\hline Change US Exp & 0.005 & 10.11 & 0.000 & -0.3 & 0.005 & 11 & -0.001 & -0.63 & 0.005 & 9.68 & 0.000 & -0.27 \\
\hline Change US Exp^2 & 0.000 & -6.6 & 0.000 & 1.01 & 0.000 & -7.96 & 0.000 & 1.17 & 0.000 & -7.31 & 0.000 & 0.98 \\
\hline \multicolumn{13}{|l|}{ First Entry Cohort Controls } \\
\hline Last Entry Cohort Controls & \multicolumn{2}{|c|}{$x$} & \multicolumn{2}{|l|}{$x$} & \multicolumn{2}{|c|}{$x$} & \multicolumn{2}{|l|}{$\mathrm{X}$} & \multicolumn{2}{|c|}{$X$} & \multicolumn{2}{|c|}{$x$} \\
\hline $\mathrm{N}$ & \multicolumn{2}{|c|}{2112} & \multicolumn{2}{|l|}{2112} & \multicolumn{2}{|c|}{2112} & \multicolumn{2}{|c|}{2112} & \multicolumn{2}{|c|}{2112} & \multicolumn{2}{|c|}{2112} \\
\hline First Stage F & \multicolumn{2}{|l|}{154.89} & & & \multicolumn{4}{|l|}{320.19} & \multicolumn{2}{|l|}{297.40} & & \\
\hline $\begin{array}{l}\text { First Stage Partial R-squared } \\
\text { standard errors clustered at communit }\end{array}$ & \multicolumn{2}{|l|}{0.08} & & & \multicolumn{2}{|l|}{0.10} & & & \multicolumn{2}{|l|}{0.17} & & \\
\hline
\end{tabular}


Table 22: IV Results of Regression on Change in log Wages

\begin{tabular}{|c|c|c|c|c|c|c|c|c|c|c|c|c|}
\hline \multirow[b]{3}{*}{ Variable } & \multicolumn{4}{|c|}{ Model 1} & \multicolumn{4}{|c|}{ Model 2} & \multicolumn{4}{|c|}{ Model 3} \\
\hline & \multicolumn{2}{|c|}{ First Stage } & \multicolumn{2}{|c|}{ Final Stage } & \multicolumn{2}{|c|}{ First Stage } & \multicolumn{2}{|c|}{ Final Stage } & \multicolumn{2}{|c|}{ First Stage } & \multicolumn{2}{|c|}{ Final Stage } \\
\hline & Beta & $\mathbf{T}$ & Beta & $\mathbf{T}$ & Beta & $\mathbf{T}$ & Beta & $\mathbf{T}$ & Beta & $\mathbf{T}$ & Beta & $\mathbf{T}$ \\
\hline Change Legal Status & & & 0.001 & 0.01 & & & -0.004 & -0.08 & & & 0.028 & 0.59 \\
\hline SAW Reported & 0.582 & 23.37 & & & & & & & & & & \\
\hline SAW Eligible & & & & & 0.598 & 27.8 & & & & & & \\
\hline SAW Eligible or Reported & & & & & & & & & 0.647 & 30.36 & & \\
\hline Change Exp & 0.012 & 2.01 & -0.010 & -1.36 & 0.010 & 1.53 & -0.010 & -1.36 & 0.011 & 1.79 & -0.010 & -1.4 \\
\hline Change $\operatorname{Exp}^{\wedge} 2$ & 0.000 & -1.63 & 0.000 & -2.1 & 0.000 & -1.37 & 0.000 & -2.1 & 0.000 & -1.51 & 0.000 & -2.09 \\
\hline Change US Exp & 0.005 & 9.32 & 0.001 & 1.28 & 0.005 & 9.38 & 0.001 & 1.33 & 0.004 & 8.3 & 0.001 & 1.12 \\
\hline Change US Exp^2 & 0.000 & -3.89 & 0.000 & 0.13 & 0.000 & -4.11 & 0.000 & 0.11 & 0.000 & -3.06 & 0.000 & 0.24 \\
\hline \multicolumn{13}{|l|}{ First Entry Cohort Controls } \\
\hline Last Entry Cohort Controls & \multicolumn{2}{|c|}{$X$} & \multicolumn{2}{|l|}{$x$} & \multicolumn{2}{|l|}{$x$} & \multicolumn{2}{|l|}{$\mathrm{X}$} & \multicolumn{2}{|c|}{$\mathrm{X}$} & \multicolumn{2}{|c|}{$x$} \\
\hline $\mathrm{N}$ & \multicolumn{2}{|c|}{2112} & & \multicolumn{2}{|c|}{2112} & \multicolumn{2}{|l|}{2112} & \multicolumn{2}{|c|}{2112} & \multicolumn{2}{|c|}{2112} \\
\hline First Stage F & \multicolumn{2}{|c|}{546.13} & \multicolumn{2}{|c|}{2112} & \multicolumn{2}{|c|}{771.59} & & & \multicolumn{2}{|l|}{921.81} & & \\
\hline $\begin{array}{l}\text { First Stage Partial R-squared } \\
\text { standard errors clustered at communit }\end{array}$ & \multicolumn{2}{|l|}{0.20} & & & \multicolumn{2}{|l|}{0.22} & & & \multicolumn{2}{|l|}{0.32} & & \\
\hline
\end{tabular}


Table 23: IV Results of Regression on Change in log Wages

OLS

IV

\begin{tabular}{|c|c|c|c|c|c|c|c|c|}
\hline \multirow[b]{2}{*}{ Variable } & \multirow[b]{2}{*}{ Beta } & \multirow[b]{2}{*}{$\mathbf{T}$} & \multicolumn{2}{|c|}{ First Stage IRCA } & \multicolumn{2}{|c|}{ First Stage SAW } & \multicolumn{2}{|l|}{ IV } \\
\hline & & & Beta & $\mathbf{T}$ & Beta & $\mathbf{T}$ & Beta & $\mathbf{T}$ \\
\hline Change Legal Status & 0.145 & 4.01 & & & & & 0.178 & 3.28 \\
\hline Change Legal Status*Ag Worker & -0.073 & -1.69 & & & & & -0.133 & -2.16 \\
\hline IRCA Eligible or Reported & & & 0.573 & 30.01 & -0.061 & -4.51 & & \\
\hline SAW Eligible or Reported & & & 0.692 & 39.62 & 0.723 & 58.13 & & \\
\hline Change Exp & -0.011 & -1.28 & 0.010 & 1.44 & 0.007 & 1.56 & -0.011 & -0.92 \\
\hline Change $\operatorname{Exp}^{\wedge} 2$ & 0.000 & -1.55 & 0.000 & -0.95 & 0.000 & -0.07 & 0.000 & -2.26 \\
\hline Change US Exp & 0.000 & 0.31 & 0.003 & 7.63 & 0.000 & 0.87 & 0.000 & 0.40 \\
\hline Change US Exp^2 & 0.000 & 0.41 & 0.000 & -4.31 & 0.000 & -0.39 & 0.000 & 0.65 \\
\hline \multicolumn{9}{|l|}{ First Entry Cohort Controls } \\
\hline Last Entry Cohort Controls & $x$ & & $x$ & & $x$ & & $x$ & \\
\hline R-Squared & 0.138 & & & & & & & \\
\hline $\mathrm{N}$ & 2112 & & 2112 & & 2112 & & 2112 & \\
\hline First Stage F & & & 1141.34 & & 1735.23 & & & \\
\hline First Stage Partial R-squared & & & 0.53 & & 0.63 & & & \\
\hline
\end{tabular}

